\title{
The Development of an Online Knowledge Based System to assist the Designers of Forging Process
}

\author{
Ismail Fidan ${ }^{1}$, Serdar Tumkor ${ }^{2}$ \\ ${ }^{1}$ Tennessee Tech University, Cookeville, Tennessee, USA \\ ${ }^{2}$ Istanbul Technical University, Gumussuyu, Istanbul, TURKIYE
}

\begin{abstract}
The objective of this project is to develop an interactive system to help the forging process designers, mechanical/manufacturing/industrial engineering and technology faculty, and students by giving them the necessary production information about the forging manufacturing process, and also to lead them with a methodological approach in the earlier stages of the forging related design process. This paper will report the current development efforts.
\end{abstract}

\section{Introduction}

The manufacture of forged products is a process of forming metal under impact or pressure $^{1-5}$. Often the workpiece is heated in order to reduce strength and increase ductility during the deformation. In this system part design, process design, and material selection are automatically calculated and some recommendations are given to users, so the designers do not deal with the real design problems. In this interactive online tool development, the system has been structured by using the Active Server Pages (ASP) technique. An interactive website is prepared that helps a remote designer to design forging parts based on various input parameters provided. The website also provides a fundamental knowledge about forging processes. Assessment data of the current development has been collected from senior level manufacturing technology course students, and forging industry experts.

\section{Web Based Forging System}

The forging website helps any designer by giving the required design and process information about the metal forging process (Figure 1). The user can find some definitions and equations about forging process from this site (Figure 2-5). Various types of forging processes are presented ${ }^{1,2}$. Figure 6 shows the page about open die forging and how to calculate the required operation force ${ }^{3}$. This interactive website has important design tools for blocker design, flash and gutter design and billet size calculations. Preform stages are defined in the blocker design page and blocker dimensions are recommended to the user according to the given input conditions (Figure 7). 


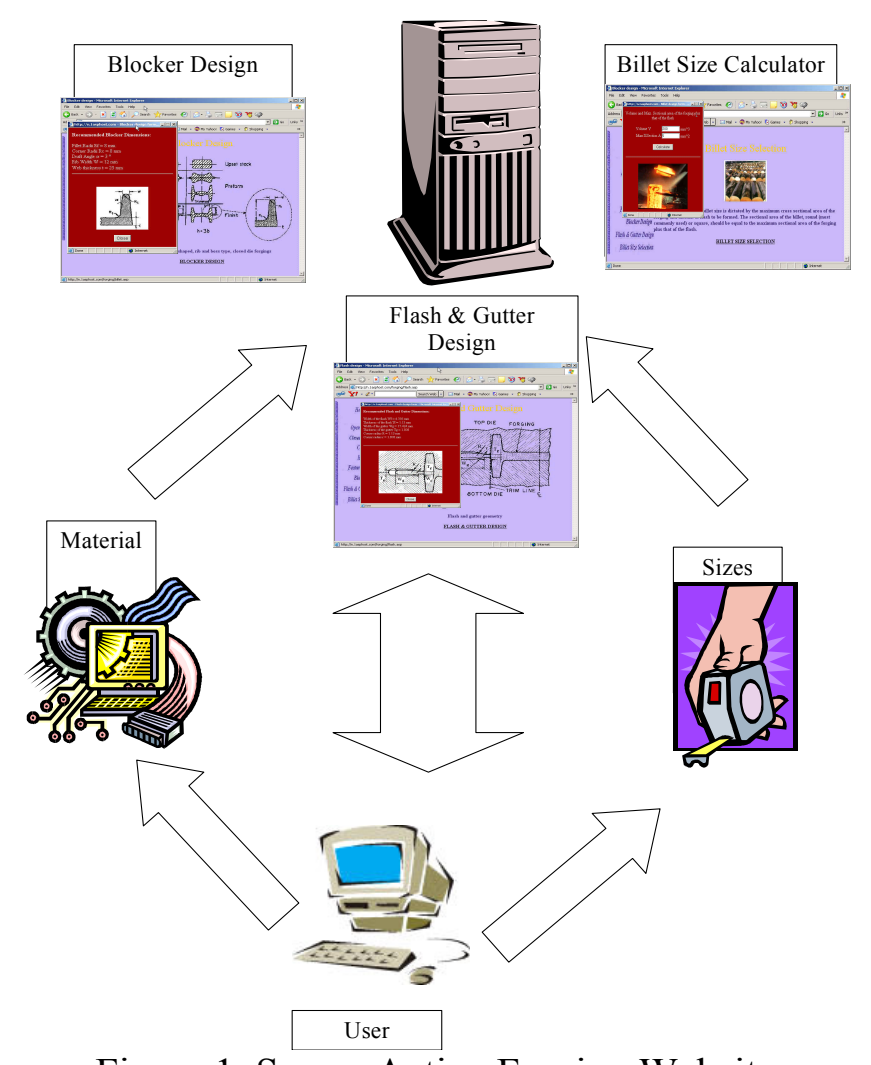

Figure 1. Server Active Forging Website

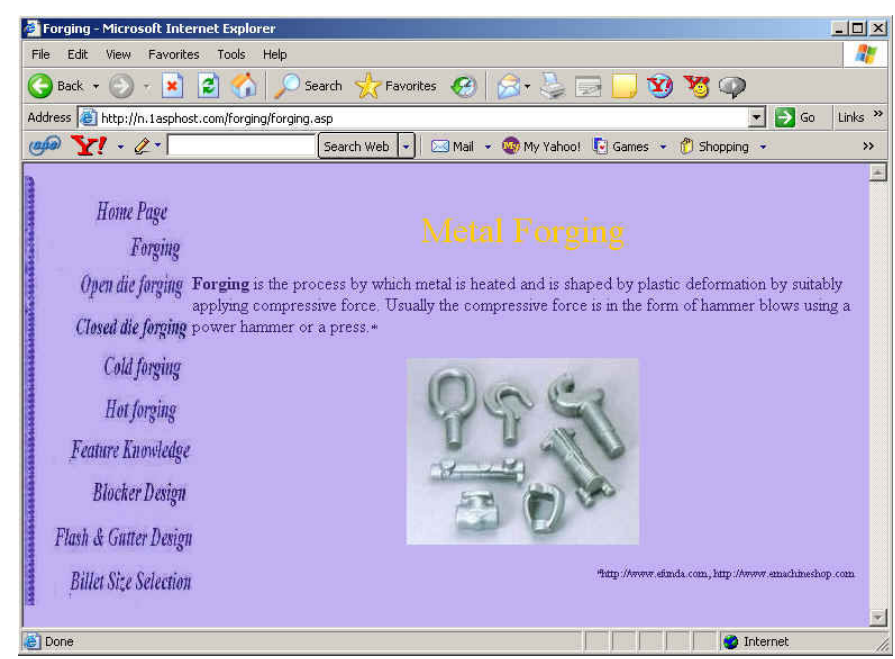

Figure 2. Metal Forging Information

In the current implementation, the following process outputs are provided by the Online Forging Knowledge Based System:

- The billet diameter and billet length that will be used for the forging part.

- The load and energy required for the forging.

- The part design data for the preform, blocker, and finisher forging. 
- The flash and gutter design data for the forging.

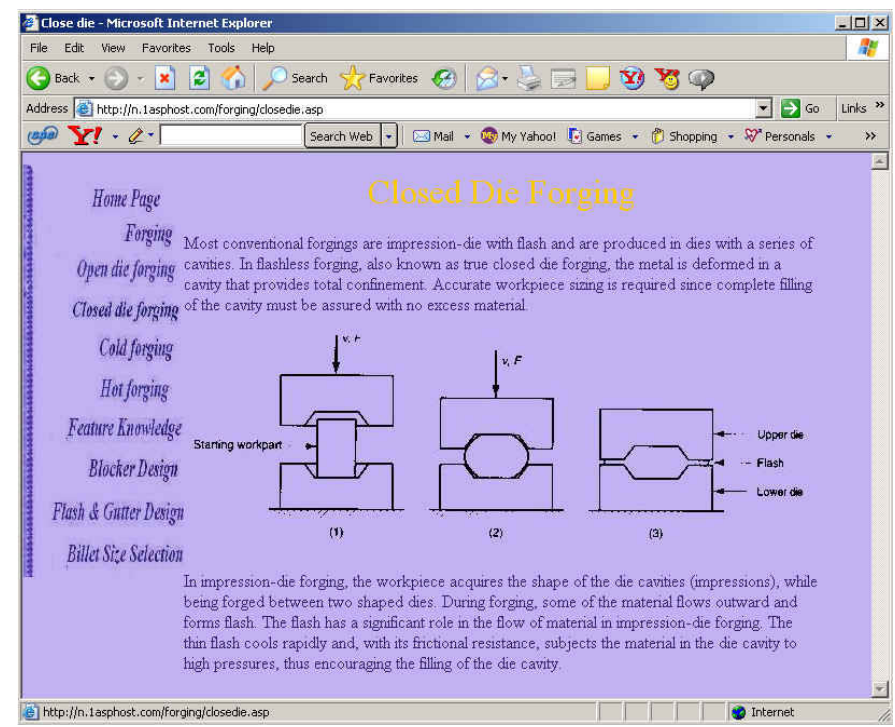

Figure 3. Closed Die Forging

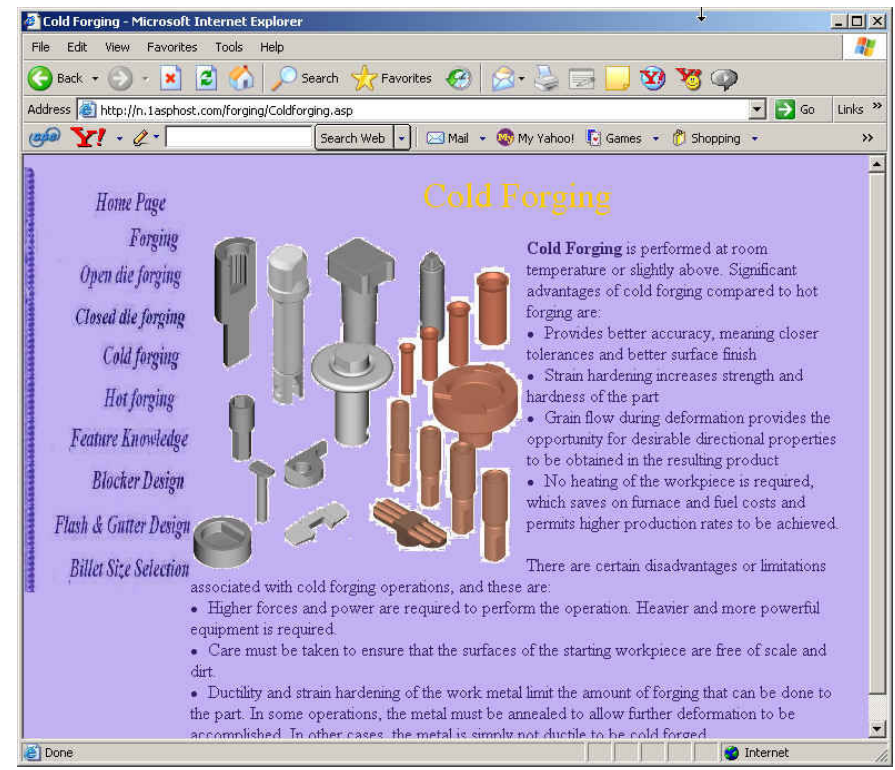

Figure 4. Cold Forging

The user can choose the part and process data/inputs from the pulldown menus. These menus are filled automatically by the server's database that contains the material properties/feature knowledge/design equations. In this website Active Server Pages (ASP) and ActiveX Data Objects (ADO) have been used for server site programming.

Once the dimensions of the part and the material are given the preform and blocker dimensions are calculated and given in a new window as recommended dimensions. (Figure 8). According to the selected material and the size of the part the recommended flash and gutter sizes are calculated (Figure 9-10). 


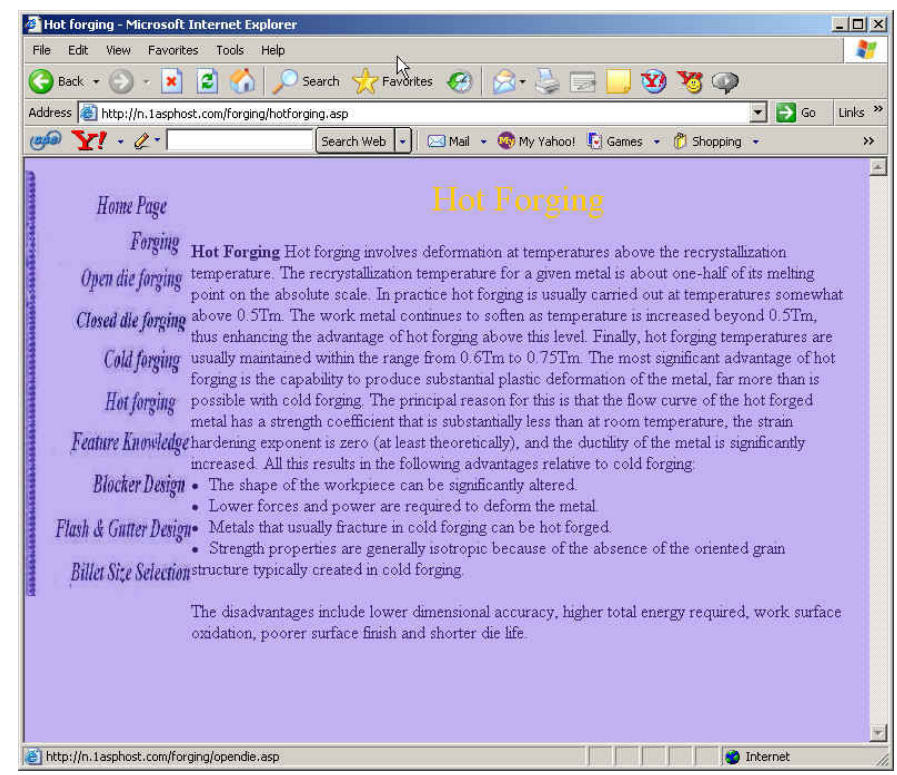

Figure 5. Hot Forging

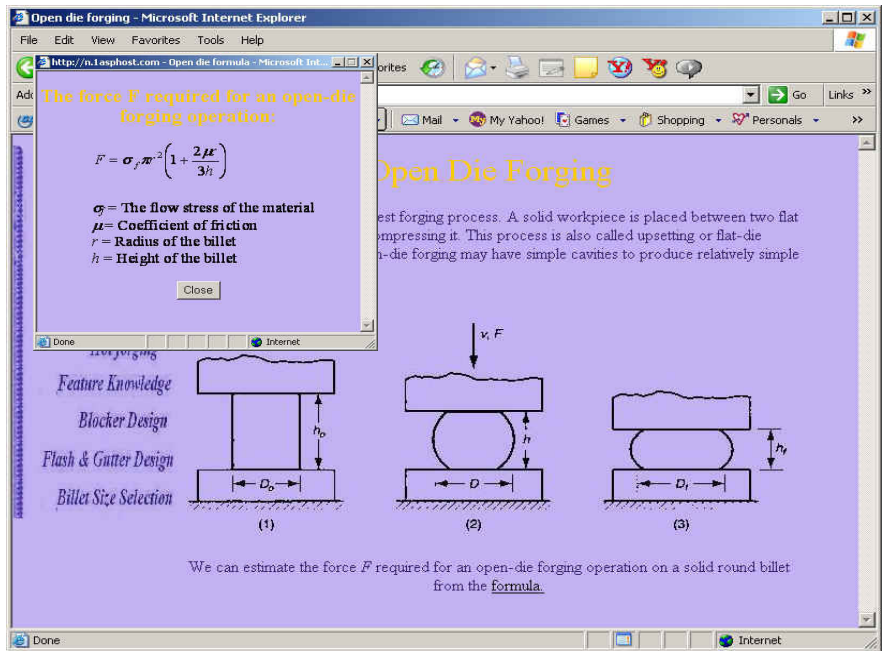

Figure 6. Open Die Forging and Pop Up Window that shows the Force Calculation

A variety of forging materials and their properties are available in the system. The collected data for the most common materials such as aluminum alloys and stainless steels are included in this system. The user is able to search the database for different attributes. These materials are usually available in standard sized billet shapes such as round and square. Round billets are most commonly used because of their advantages in manufacturing, shipping and handling. A variety of round and square size billet selections is also included in this development (Figure 11-12). 


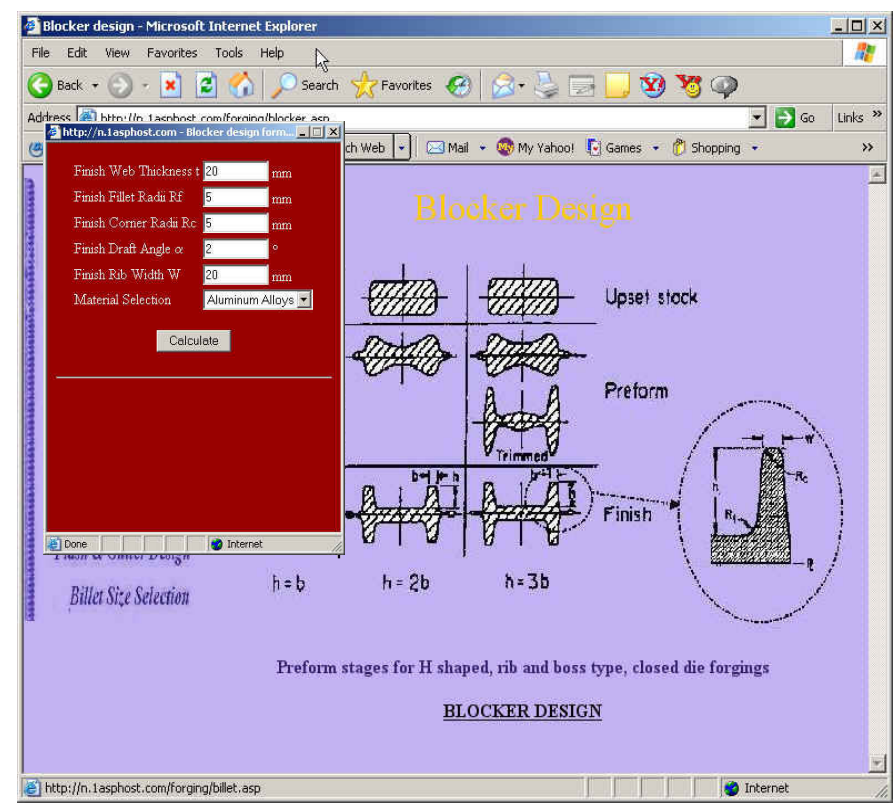

Figure 7. Blocker Design Page and its Calculation Dialog Window

\begin{tabular}{|l|}
\hline User Input: \\
Finish Web Thickness [mm] \\
Finish Fillet Radii Rf $[\mathrm{mm}]$ \\
Finish Corner Radii $\operatorname{Rc}[\mathrm{mm}]$ \\
Finish Draft Angle $\left[^{\circ}\right]$ \\
Finish Rib Width W $[\mathrm{mm}]$ \\
Material
\end{tabular}

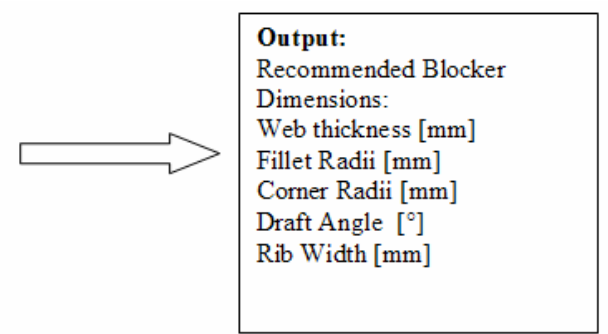

Figure 8. Recommended Blocker Calculation Parameters

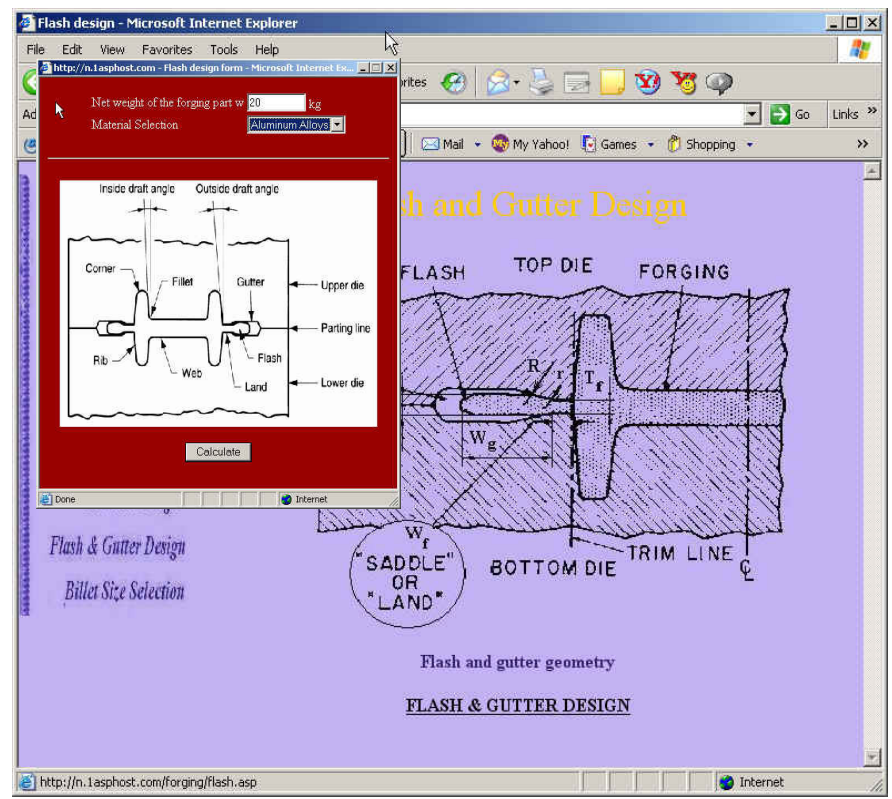

Figure 9. Flash and Gutter Design Window 


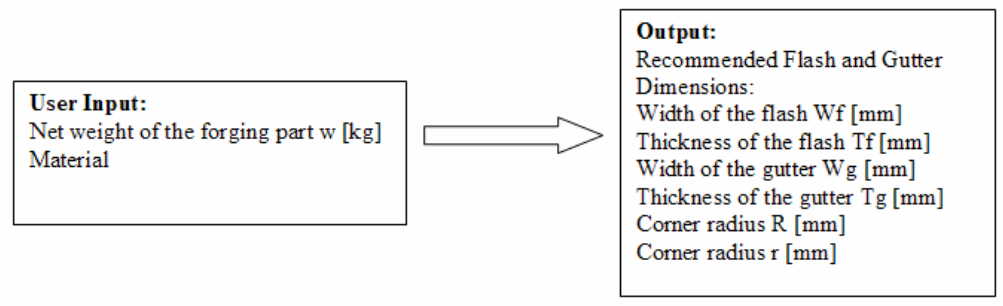

Figure 10. Flash and Gutter Size Parameters

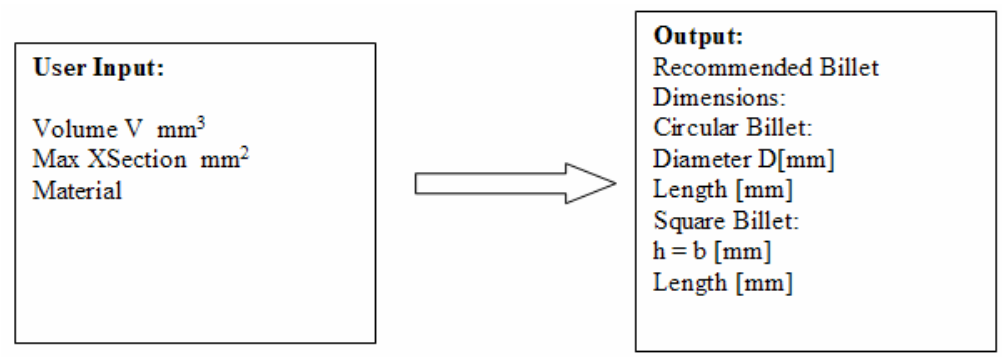

Figure 11. Billet Size Selection Parameters

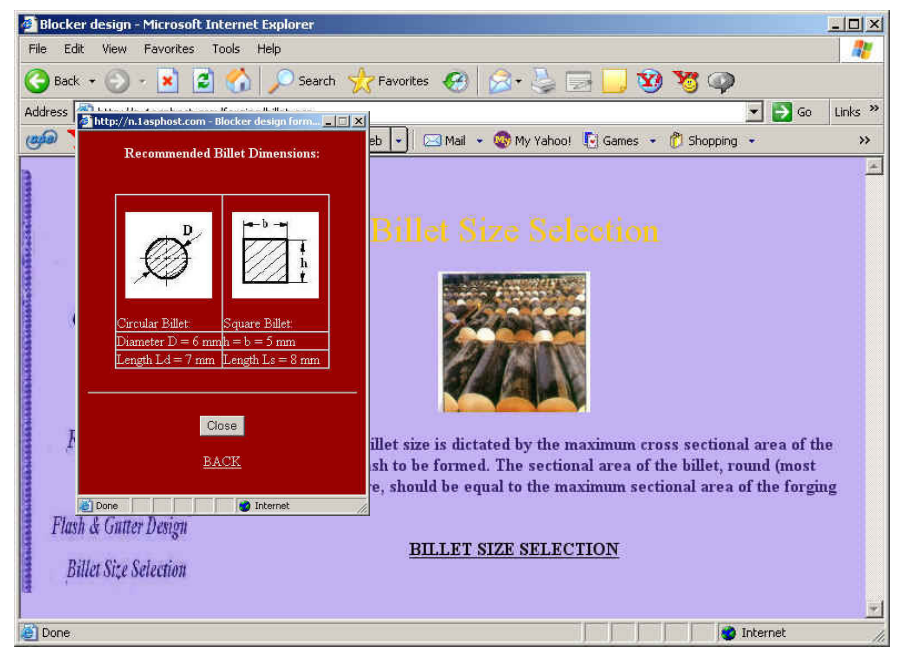

Figure 12. Recommended Billet Sizes with Square and Circular Cross-sections

\section{Conclusion}

Online Forging Knowledge-Base is a fully integrated online design system which provides the user with detailed knowledge on processing and design considerations. Through the development of such a system for forging, design rules and heuristics, best industry practices, and analytical methods have been integrated into the part and process design. The system has been tested by senior level technology students and their feedback was received. Students indicated that learning through this interactive website was much more beneficial than straight lecture. 
This paper is intended to provide the reader with a generic description of the behavior of Online Knowledge Based System for Forging Process. System windows and sample outputs are presented. More detailed information can be received from http://n.1 asphost.com/forging/.

\section{Acknowledgements}

This project has been funded by the Office of Research in Tennessee Tech University. Authors greatly appreciate this financial aid required to complete the current project.

\section{Bibliographical Information}

1. T. Altan, F. W. Boulger, J. R. Becker, N. Akgerman, H. J. Henning, Forging Equipment, Materials, and Practices, Metals and Ceramics Information Center, October 1973.

2. T. Altan, S. I. Oh, H. L. Gegel, Metal Forming Fundamentals and Applications, American Society for Metals," 1983.

3. S. Kalpakjian, Manufacturing Engineering and Technology, pp. 384-416, Addison-Wesley Publishing Company, 1989.

4. E. P. DeGarmo, J. T. Black, R. A. Kohser, Materials and Processes in Manufacturing, $8^{\text {th }}$ Edition, pp. 445-484, 545-552, Prentice Hall, 1997.

5. M. P. Groover, Fundamentals of Modern Manufacturing, Materials, Processes, and Systems, pp. 435-446, 458-475, Prentice Hall, 1996.

$\underline{\text { Biographical Information }}$

ISMAIL FIDAN

Dr. Ismail Fidan is an Associate Professor in the Manufacturing and Industrial Technology Department, College of Engineering, Tennessee Tech University, Cookeville, TN. Dr. Fidan received his PhD in Mechanical Engineering from Rensselaer Polytechnic Institute in 1996. His teaching and research interests are in computer-integrated design and manufacturing, electronics manufacturing, rapid prototyping, emanufacturing, online teaching, and manufacturing processes.

\section{SERDAR TUMKOR}

Serdar Tumkor is an Assistant Professor of Mechanical Engineering at Istanbul Technical University, Istanbul, Turkey. He has been a full-time faculty member since 1996. Dr. Tumkor received his $\mathrm{PhD}$ in Mechanical Engineering from Istanbul Technical University in 1994. His teaching interests are Machine Design, Engineering Design, and Computer-Aided Technical Drawing. His current research interests include computer integrated design, process planning and manufacturing, gear and continuously variable transmission manufacturing, design for optimum cost, online design catalogs, and web-based collaboration. 